\title{
Progressive hemifacial atrophy: a case report
}

\author{
M Y M ZAFARULLA \\ From the Department of Oral and Maxillo Facial Surgery, Bolton District General Hospital, Farnworth, \\ Bolton, Lancashire
}

SUMmaRY A case of a 28-year-old Caucasian female with progressive hemifacial atrophy and atrophy of the rhomboid muscles on the ipsilateral side is reported. The literature on this condition and its treatment is reviewed.

The first published reports on progressive hemifacial atrophy were attributed to Parry' in 1825 and Romberg $^{2}$ in 1846 . Characterised by progressive atrophy of the skin, subcutaneous tissue, muscle, cartilage, or bone, the condition can leave a marked deformity on one side of the face. Extension to the ipsilateral upper extremity and to the entire half of the body have also been described. The condition usually presents during the first two decades of life, often beginning in the paramedian area of the face. It may cease at any stage and leave only a minimal disfigurement.

Progressive hemifacial atrophy should be distinguished from localised scleroderma, hemifacial microsomia, traumatic fat necrosis, atrophy secondary to facial paralysis, and unilateral patrial lipodystrophy. There has been speculation on the relationship between hemifacial atrophy and localised scleroderma. Wartenberg ${ }^{3}$ in his extensive review concluded that the two conditions are essentially the same, and this view has been supported by Rees. ${ }^{4}$ However, Crickler et al. ${ }^{5}$ and Dawson ${ }^{6}$ concluded that scleroderma is a different entity.

\section{Case report}

In April 1982 a 28-year-old Caucasian female patient with a history of progressive enophthalmos on the right side was referred to a consultant ophthalmologist by her general practitioner. Photographs of the patient taken in the past show the enophthalmos to be of gradual onset, though the patient was more aware of the change during the previous 12 months. A lipoma was removed from the patient's scapula region 10 years previously, but otherwise the

Correspondence to Mr M Y M Zafarulla. medical, surgical, and family history were uneventful.

On examination facial asymmetry was obvious, with noticeable enophthalmos on the right side, but function of the extraocular muscles was unaffected. Some atrophy of the right facial musculature was obvious, particularly over the zygomatic bone and the region of the upper lip (Fig. 1). Extensive radiological investigation of the skull and facial bones revealed no significant abnormality apart from the right ramus of the mandible which was found to be diminished both in height and width with impaction of the right mandibular wisdom tooth. From the above findings a diagnosis of progressive hemifacial atrophy was arrived at.

General examination also revealed a degree of atrophy of the rhomboid muscle on the same side, as a consequence of which the vertebral border of the scapula was thrown into prominence (Fig. 2).

A chest $x$-ray showed prominent hilar shadows, and as the erythrocyte sedimentation rate (ESR) was slightly raised at $23 \mathrm{~mm}$ in the first hour the possibility of pulmonary sarcoidosis was suggested. Further investigations undertaken by a consultant physician, including the Kveim test and serum angiotensin converting enzyme level, failed to support this, and tuberculosis was also excluded. Electromyographic and nerve conduction studies on the atrophied rhomboid muscles indicated no evidence of denervation.

The patient was subsequently referred for both plastic and maxillofacial surgical opinions. The consensus of opinion after extensive consultation and discussion was that her facial appearance was acceptable and she should be kept under periodic review. However, excision of the impacted right mandibular wisdom tooth was necessary, and this was carried out for her uneventfully under general anaesthetic. 


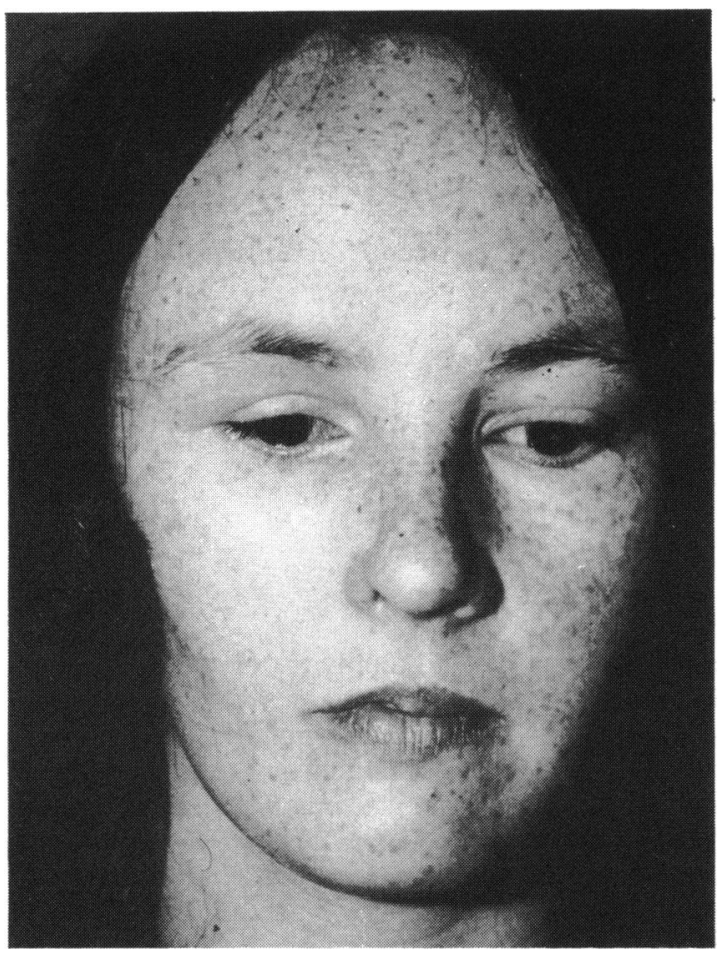

Review of the patient in March 1984 showed no significant change in her condition.

\section{Discussion}

Trauma, infection, genetic factors, autoimmunity, and peripheral trigeminal neuritis have all been incriminated in the initiation of the process of progressive hemifacial atrophy. In one case ${ }^{7}$ the attributed traumatic factor was extraction of a tooth. Wartenberg, ${ }^{3}$ however, considered the primary local factor to be a disturbance of fat metabolism resulting from trophic malfunction of the cervical sympathetic system.

Aracena et al. ${ }^{8}$ and Muchnick et al. ${ }^{9}$ in an extensive ophthalmological review of hemifacial atrophy reported the most common ocular involvement to be enophthalmos due to atrophy of the orbital fat. Changes in the eyelids were also common, with varying degrees of eyelid atrophy, which in turn can lead to corneal changes such as keratitis and ulceration. Coloboma as an associated entity has also been reported, ${ }^{10}$ as have optic neuritis and facial paralysis."

Goldhammer et al. ${ }^{12}$ reported a case of progressive hemifacial atrophy with extensive atrophy of the walls of the maxillary sinus but only minimal soft

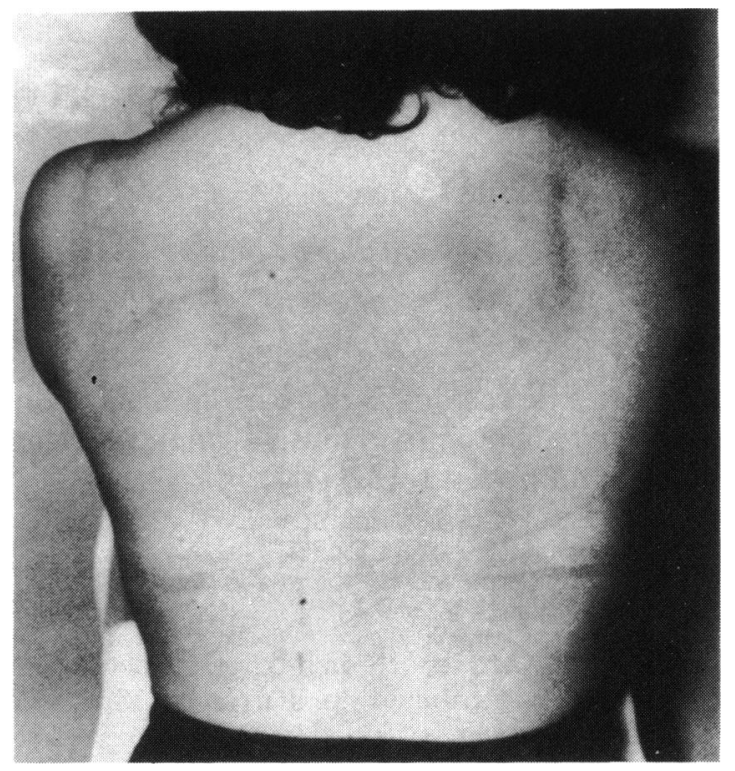

Fig. 1 Front view of the face.

Fig. 2 View of upper back showing some atrophy over the region of rhomboid muscles on the patient's right side.

tissue involvement. Prolapse of the subcutaneous tissue and orbital fat into the maxillary sinus simulated the presence of a tumour and necessitated surgical exploration. Foster ${ }^{13}$ reported the effect on dental development and stressed that, if the condition is present during the growth phase, it may result in reduced growth of the roots of the teeth on the affected side. Bramley and Forbes ${ }^{14}$ reported an interesting case of progressive hemifacial atrophy presenting with spontaneous fracture of the atrophied mandible.

In the detailed reviews by Arachambault and Fromm ${ }^{7}$ and Wartenberg ${ }^{3}$ various extrafacial manifestations have been reported. They include atrophy of kidney, adrenal glands, ovary, and even the entire half of the body. Hickman and Shiels ${ }^{15}$ reported a case of marked ipsilateral with contralateral lower extremity involvement. Migraine and epilepsy have also been observed, while Dawson ${ }^{6}$ reported a case of pulmonary sarcoid in conjunction with hemifacial atrophy.

Treatment in progressive hemifacial atrophy is primarily directed towards augmentation of the affected areas for aesthetic reasons. Secondary procedures on uninvolved areas of the face may improve the result. The reconstructive procedure is determined by the particular phase of the disorder (active 
or 'burned out'), location, and the degree of the deformity to be corrected.

The use of autografts-for example silicone polymer, pedicled, and free flaps ${ }^{16}$ - have all been described. Rees et al. ${ }^{17}$ following a 10 -year study on the use of injectable silicone fluid in hemifacial atrophy reported significantly good results. They further emphasised that the silicone fluid should be injected in small repeated doses followed by thoroughly massaging the area immediately afterwards to obtain the optimum results. Bart and Kopf ${ }^{18}$ also reported good aesthetic results with this method.

The introduction of free tissue transfer by microvascular anastomosis opened a new era in reconstructive surgery. Harashina and Fujino ${ }^{19}$ and Shintomi $e t$ al. ${ }^{20}$ reported good results in hemifacial atrophy with the transfer of vascularised dermis flaps from the deltopectoral and groin regions to the facial region. Although it is widely held that surgery to correct facial hemiatrophy should be performed only after the progress of the disease has come to a halt, Converse ${ }^{16}$ and Shintomi et al. ${ }^{20}$ favoured operation at an early stage. They further believe that a free flap with a new independent source of blood which will constantly feed the affected tissue will have a beneficial influence on the disease process in addition to offering the greatest chance of success in the reconstruction of the deformity caused by this puzzling condition.

I thank Mr J C Lowry, consultant oral surgeon, Mr D M Somerville, consultant ophthalmic surgeon, and $\mathrm{Mr} \mathrm{R} \mathrm{P}$ Jones, consultant plastic surgeon for their permission to report this case. My gratitude is due to Mr J C Lowry for his help in the preperation of this paper. I also thank Mr R Graham, medical photographer for the illustrations and Mrs N R Zafarulla for kindly typing the manuscript.

\section{References}

1 Parry CH. Collection from unpublished papers. London: Underwood, 1825; 1: 478.

2 Romberg MH. Throphonenrosen: Klinische Ergebnisse. Berlin: Forstner, 1946: 75.

3 Wartenberg R. Progressive facial hemiatrophy. Arch Neurol 1945; 54: 75-96.

4 Rees TD. Facial atrophy. Clin Plast Surg 1976; 3: 637-46.

5 Crickler GF, Moss ML, Khuri A. Facial hemiatrophy. Plast Reconstr Surg 1962; 29: 5-13.

6 Dawson TAJ. Facial hemiatrophy (Parry-Romberg syndrome). Br J Dermatol 1966; 78: 545-6.

7 Arachambault L, Fromm NK. Progressive facial hemiatrophy. Arch Neurol 1932; 27: 529-84.

8 Aracena T, Roca Fp, Barragan M. Progressive hemifacial atrophy (Parry-Romberg syndrome). Ann Ophthalmol 1979; 11: 953-6.

9 Muchnick R, Aston SJ, Rees TD. Occular manifestations and treatment of hemifacial atrophy. 1979; 88: 889-97.

10 Smith B, Guberina C. Coloboma in progressive hemifacial atrophy. Am J Ophthalmol 1977; 84: 85-9.

11 Shumway EA. Association of optic neuritis, facial paralysis and facial hemiatrophy. Arch Ophthalmol 1935; 13: 8-13.

12 Goldhammer KJ, Tadmor T, Braham J, Leventon G. Progressive hemifacial atrophy (Parry-Romberg's disease) principally involving bone. J Laryngol Otol 1981; 95: 643-7.

13 Foster TD. The effects of hemifacial atrophy in dental growth. Br Dent J 1979; 146: 148-50.

14 Bramley JM, Forbes A. A case of progressive hemiatrophy presenting with spontaneous fracture of the lower jaw. $\mathrm{Br}$ Med J 1960 ; i: 1476-8.

15 Hickman JM, Sheils WS. Progressive facial hemiatrophy. Arch Intern Med 1964; 113: 716-20.

16 Converse JM. Reconstruction plastic surgery. 2nd ed. Philadelphia, London, Toronto: Saunders, 1977; 4: 2337-9.

17 Rees TD, Ashley FL, Delgado JP. Silicone fluid injection for facial atrophy. Plast Reconstr Surg 1973; 52: 118-27.

18 Bart RS, Kopf AW. Hemifacial atrophy. J Dermatol Surg Oncol 1978; 4: 908-9.

19 Harashina T, Fujino T. Reconstruction of Romberg's disease with free groin flap. Ann Plast Surg 1981; 7: 289-94.

20 Shintomi Y, Ohura T, Honda K, lida K. The reconstruction of progressive facial hemiatrophy by free vascularised dermis fat flaps. Br J Plast Surg 1981; 34: 398-409. 